\title{
The Influence of the Number of Presented Symptoms in Product-Claim Direct-to-Consumer Advertising on Behavioral Intentions
}

Nikki Wingate, Ph.D.

Ernest C. Trefz School of Business

University of Bridgeport
Yìng Xie, Ph.D.

and

Naveen Jindal School of Business

The University of Texas, Dallas

\begin{abstract}
Purpose
In order to improve the effectiveness of product-claim Direct-to-Consumer Advertising (DTCA), the current research examines the effect of a presentational element - the number of treatable symptoms for the advertised medical condition featured in the ad - on consumers' intentions to seek treatment.
\end{abstract}

\section{Methodology}

Ninety-five participants recruited at a mall in the northeastern US provided data on behavioral and attitudinal intentions regarding a product-claim print DTCA for an antidepressant.

\section{Findings}

Featuring a high (vs. low) number of symptoms improved the effectiveness of the product-claim DTCA. Seeing more symptoms led to heightened perceptions of informativeness, lower persuasive intent, and higher intentions to discuss the advertised ailment and the advertised drug with the doctor. Perceptions of disease prevalence mediated this influence. The perceived impact of each symptom featured in the DTCA was controlled across experimental conditions.

\section{Research Implications}

This research contributes to the healthcare marketing literature by demonstrating how managing a presentational element in DTCA influences consumers' metacognitive processing of the health information and consequently their intentions to engage in healthrelated behaviors.

\section{Practical Implications}

Within the regulatory boundaries, pharmaceutical marketers may wish to increase the number of treatable symptoms to feature in their product-claim DTCA in order to improve the effectiveness.

Originality/value: This research builds on the extant literature of examining consumer perceptions of DTCA, and suggests a practical and metacognitive means to improve consumer perceptions to ultimately enhance DTCA effectiveness.

\section{FDA Regulations on Product Claim DTCA

\begin{tabular}{l|l}
$\begin{array}{l}\text { FDA regulations state that product } \\
\text { claim ads must include[1]: }\end{array}$ & $\begin{array}{l}\text { Decisions under control of advertisers } \\
\text { in exec ution }\end{array}$ \\
$\begin{array}{ll}\text { - At least one FDA-approved use for the } \\
\text { drug }\end{array}$ & $\begin{array}{l}\text { - Number of treatable symptoms } \\
\text { - Selection of treatable symptoms }\end{array}$ \\
\hline - The most significant risk(s) of the drug & $\begin{array}{l}\text { - Selection and interpretation of the 'most } \\
\text { significant' risks } \\
\text { - Number of risk(s) to be presented }\end{array}$ \\
\hline
\end{tabular}

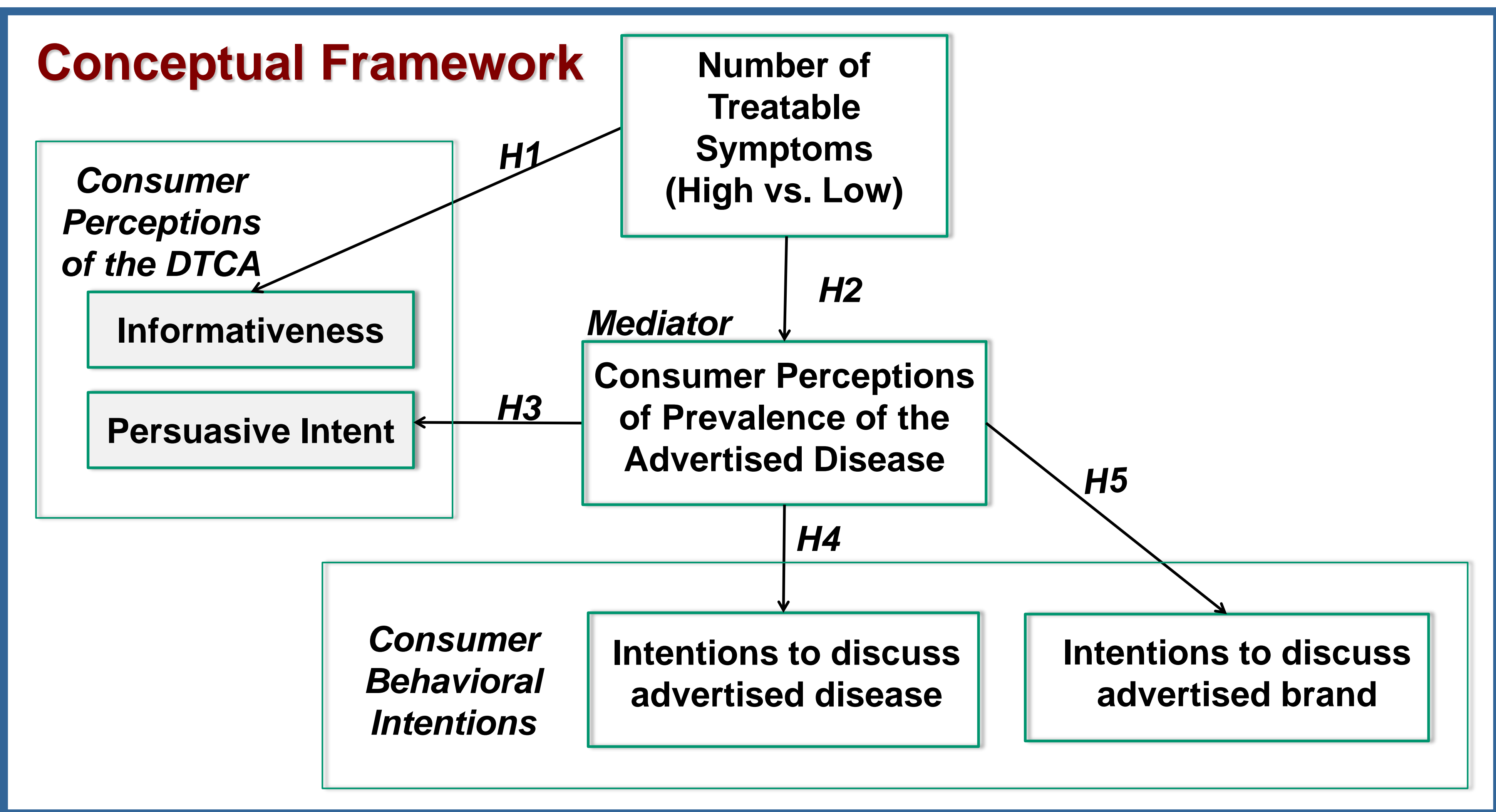

\section{Experiment Stimuli (Low vs. High number of Symptoms)}
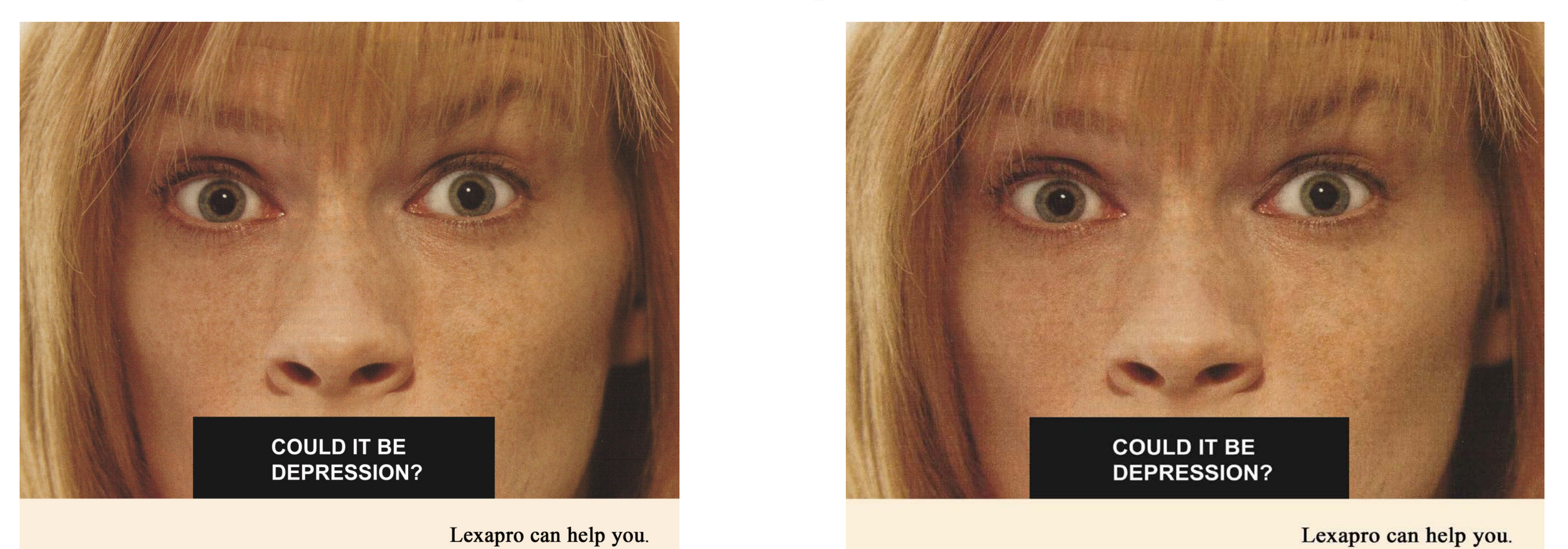

If you have any of the symptoms listed below,

you may be suffering from depression. Thoughts of death
Thoughts of suicide Feelings of guilt Feelings of hopelessness

Ask your doctor about how Lexapro can help you. Lexapro

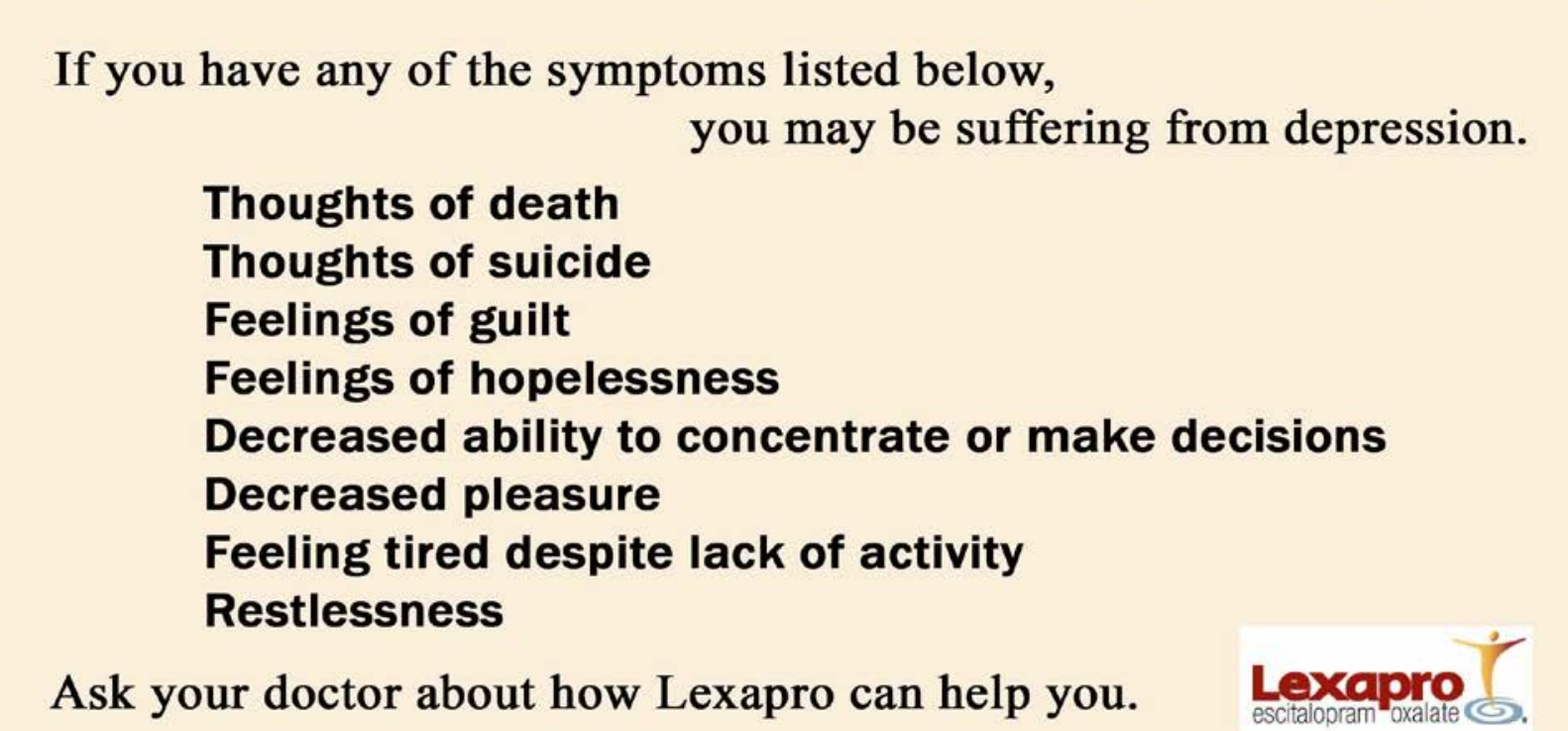

Ask your doctor about how Lexapro can help you. Lexapro

Select Results of Statistical Analyses

\begin{tabular}{|c|c|c|c|c|c|}
\hline \multirow{3}{*}{$\begin{array}{l}\text { Number of } \\
\text { Featured } \\
\text { Symptoms }\end{array}$} & \multicolumn{3}{|c|}{ Consumer Perceptions } & \multicolumn{2}{|c|}{ Behavioral Intent } \\
\hline & (H1 & $\mathrm{H} 2$ & H3) & (H4 & H5) \\
\hline & Informativeness & Prevalence & $\begin{array}{c}\text { Persuasive } \\
\text { Intent }\end{array}$ & $\begin{array}{l}\text { Discuss } \\
\text { Disease }\end{array}$ & Discuss Drug \\
\hline Low & 3.93 & 6.58 & 5.08 & 1.70 & .95 \\
\hline High & 5.18 & 7.60 & 4.00 & 2.95 & 1.58 \\
\hline $\boldsymbol{F}$ & 6.66 & 8.29 & 4.64 & 12.79 & 8.17 \\
\hline$p$ & .0114 & .0049 & .0339 & .0006 & .0053 \\
\hline
\end{tabular}

